This item was submitted to Loughborough's Research Repository by the author.

Items in Figshare are protected by copyright, with all rights reserved, unless otherwise indicated.

\title{
Healthcare providers' perception of design factors related to physical environments in hospitals
}

PLEASE CITE THE PUBLISHED VERSION

http://dx.doi.org/10.1016/j.jenvp.2012.06.004

PUBLISHER

(C) Elsevier

VERSION

AM (Accepted Manuscript)

LICENCE

CC BY-NC-ND 4.0

\section{REPOSITORY RECORD}

Mourshed, Monjur, and Yisong Zhao. 2019. "Healthcare Providers' Perception of Design Factors Related to Physical Environments in Hospitals". figshare. https://hdl.handle.net/2134/9948. 
This item was submitted to Loughborough's Institutional Repository (https://dspace.lboro.ac.uk/) by the author and is made available under the following Creative Commons Licence conditions.

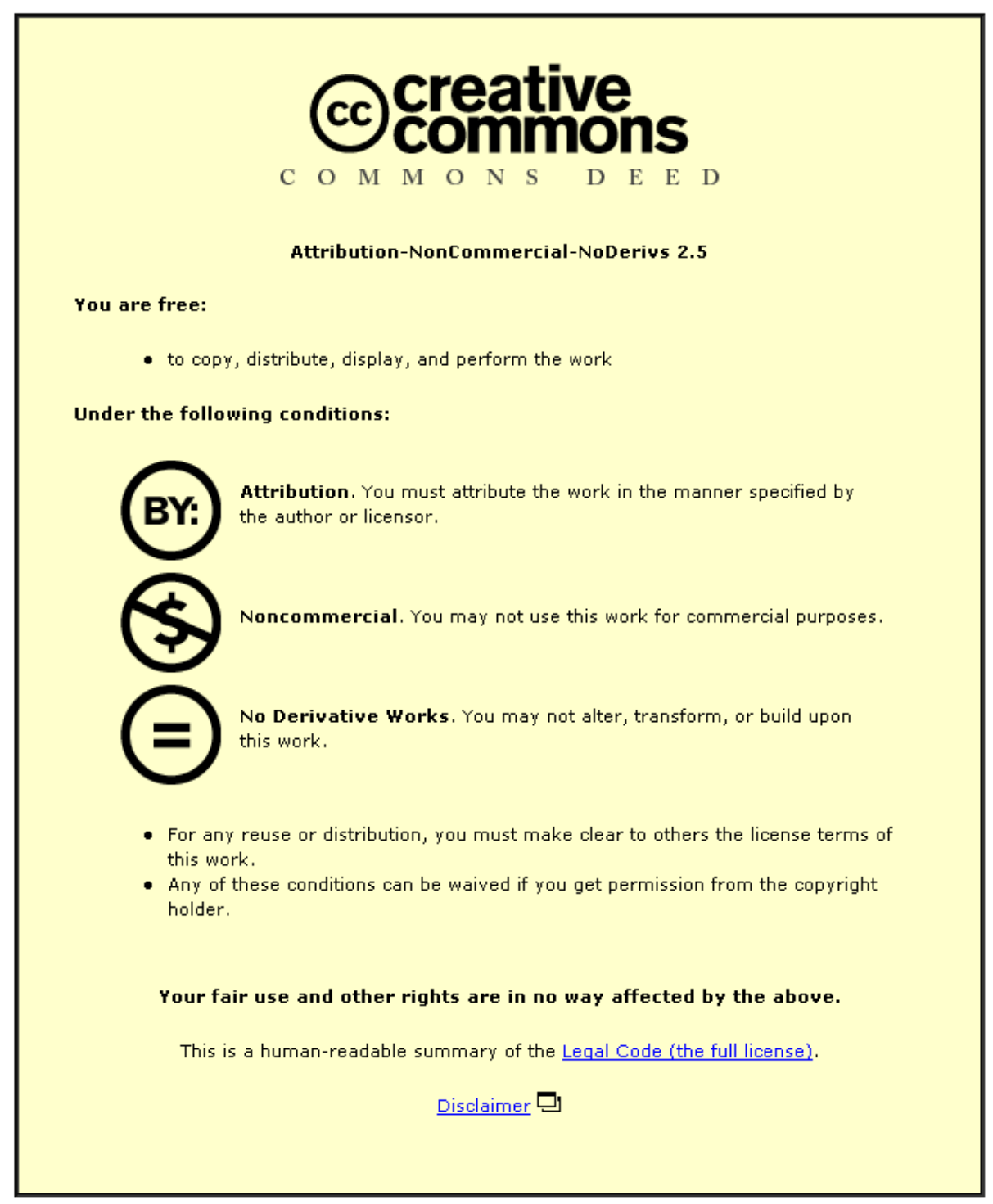

For the full text of this licence, please go to: http://creativecommons.org/licenses/by-nc-nd/2.5/ 


\title{
Healthcare providers' perception of design factors related to physical environments in hospitals
}

\author{
Monjur Mourshed ${ }^{1}$, Yisong Zhao \\ Building Energy Research Group (BERG), School of Civil and Building Engineering, \\ Loughborough University, Loughborough, Leicestershire, LE11 3TU, UK
}

\begin{abstract}
Research indicates that staff wellbeing, productivity and satisfaction are linked with a hospital's physical environment, in particular the aspects that are determined during early design stages of a building's lifecycle. Incorporating healthcare providers' perspectives during the design of a facility is, therefore, essential to create an effective therapeutic environment. Past research on physical environments in hospitals focused mostly on user satisfaction and was linked with service delivery in a specific setting. Research findings seldom provided useful insights into user perspectives on design related aspects that had the potential to affect their interaction with the environment. This research was aimed at filling this gap by exploring healthcare providers' perception of physical environment design factors in hospitals. A 16-item questionnaire was used to gather perspectives of nurses, doctors and administrative staff in two Chinese hospitals, with a response rate of $77.3 \%(N=304)$. Descriptive, principal component analysis and statistical tests were applied on the responses to investigate the relationship between perceptions of design factors and demographic and work related variables. Three principal components were identified, namely spatial, maintenance and environmental design. The identified components had good correspondence with previous research on behavioral and environmental psychology. Female healthcare providers were found to be more perceptive about factors related to sensory environments such as visual, acoustic and olfactory, compared to their male counterparts. The working pattern and length of service had associations with perceptions of maintenance and environmental design factors. Respondents ranked abstract and more subjective design factors such as aesthetics and the presence of coordinated art objects lower than the factors generally associated with the safe and efficient delivery of service.
\end{abstract}

Keywords: Healthcare providers, Perception, Design factors, Physical environment, Hospital

\section{Introduction}

Research suggests a strong association between health outcomes and the physical environment in which a person lives or receives treatment (Gesler et al., 2004; Rollins, 2004; Ulrich et al., 2008; Whitehouse et al., 2001). Consequently, attention has recently been turned on the actual architectural design of a healthcare facility (Reiling, 2007). The idea of 'place making' or the provision of an optimum psychological fit between people and their physical

\footnotetext{
${ }^{1}$ Corresponding author. Email address: m.m.mourshed@lboro.ac.uk

Tel: +44 1509 228792. Web: http://monjur.mourshed.org/
} 
surroundings has received renewed interests among the design community (Sime, 1986), in particular from healthcare designers (Prasad, 2008). Place making can be seen as a move away from the mere geometric design of spaces towards a more holistic consideration of user perception and behavior in the physical context. Examples of place making by integrating research-based evidence in hospital design can be found in the idea of 'sense sensitive design' (Mazuch, 2005). The need for integrating user perception and preference of their physical surroundings in buildings has also been highlighted, directly or indirectly, in past research on post occupancy evaluations of buildings (Dinç, 2009), user satisfaction (Crow et al., 2002) and indoor thermal comfort (De Dear, 2004).

There is also a growing body of evidence on the impact of the working environment on healthcare providers' efficiency, productivity and satisfaction that contribute to patient outcomes. In a recent research on the effect of work environments on hospital outcomes across nine countries, Aiken et al. (2011) have concluded that poor hospital work environments were common and were associated with negative staff outcomes and poor quality of care. Staff turnover, in particular nursing staff turnover, has been found to be a growing risk in many developed countries. Determinants of turnover are found to be multifaceted and dependent on the context of the study and points of view of the researcher (Hayes et al., 2006). However, work environments are found to be commonly associated with staff turnover (Hayes et al., 2006; Jones, 2005), in addition to leadership and management approaches (Cummings et al., 2010). Physical environments are also linked with staff wellbeing issues such as injury rates and stress (Trinkoff et al., 2005). Ulrich et al. (2008) have discussed physical environment factors that affect staff outcome in a review article. They identified that well designed hospital environments had the potential to increase staff effectiveness and satisfaction; reduce medical errors and hospital acquired infections; and decrease staff stress and injuries.

Improving the quality of care and efficiency of service delivery while reducing costs have become increasingly important because of the greater budgetary pressure in recent years. Healthcare expenditure accounts for a significant share of the national budget in most 
countries (Garrett et al., 2009). There is, therefore, a growing need for transparency in decision-making that is based on the evidence of the impact of physical environments on healthcare quality. Assessments of healthcare quality were typically based on professional practice standards and seldom incorporated aspects related to physical environments (Devlin \& Arneill, 2003). However, the opinion of healthcare facility users is increasingly being accepted as an important indicator for measuring healthcare quality and as a critical component of performance improvement and clinical effectiveness (Woodring et al., 2004). Healthcare providers constitute the most frequent facility user group who spend most of their working time in hospital indoor environments. Their opinion on the design of a hospital provides valuable information and expertise to hospital designers, as healthcare providers are familiar with the physical aspects of the environment, as well as its relationship with the requirements of their work.

Most aspects of the physical environment having an impact on staff outcome are determined during early design stages of a building's lifecycle. Subsequent modifications at later stages are expensive and sometimes difficult to achieve due to the multidisciplinary nature of design decision-making. An understanding of users’ perception of design factors is, therefore, essential for informed decision making during early design stages. Past research on physical environments in hospitals focused mostly on staff satisfaction and was linked with service delivery in a specific context (see Vischer, 2007, for a discussion). User satisfaction studies provided an indication of some relevant physical environment features that could be considered during design. Nevertheless, they were mere proxies, which needed translating into design factors before use and not without some loss of semantics. Moreover, physical environment factors were not studied in an integrated way in a single study to generate a comprehensive evidence base, upon which decisions could be made.

This study was aimed at filling this gap by contributing to the evidence base on factors related to physical environments in hospitals. Healthcare providers’ perceptions of 16 design factors, identified through a review of existing literature, were explored by conducting a questionnaire in two Chinese hospitals. 
The rest of the paper is organized as follows. The methods for the development of the instrument and the conduct of the questionnaire are discussed. Descriptive and statistical analyses of the obtained data are discussed next, followed by a contextual discussion. Research limitations are discussed next. The article ends with a summary of findings and concluding remarks.

\section{Methods}

2.1. Questionnaire development

The questionnaire instrument was developed in four stages.

First, the items of the questionnaire were identified based on a review of literature and industry guidelines, conducted between January and May 2009. The purpose of the review was to identify the design factors that:

- Modify physical environments in healthcare facilities;

- Affect users' perception and satisfaction of the physical environment; and

- Affect the delivery of service and clinical outcome.

Table 1 lists the investigated design factors, identified from the review of literature and industry guidelines. Key sources are also listed to contextualize the inclusion of the factors with previous research findings.

Second, one of the authors visited the two participating hospitals four times and interviewed members of staff to explore their perspectives on the physical environment, in particular the factors that can be addressed during design/refurbishment of hospitals.

Third, a draft questionnaire was developed by incorporating the findings from the first two stages. The questionnaire was first produced in English and then translated to Chinese. Two healthcare professionals and two administrators reviewed the draft for accuracy and content validity. The draft questionnaire was then evaluated in a pilot study to analyze the comprehensibility and clarity of the items and features related to the psychometric properties of the instrument. The participants $(N=21)$ of the pilot study included head nurses, physicians and administrators. All participants were asked to state any deficiencies of the 
content of the questionnaire, other potential sources of perceptions and significance of each item. The pilot study resulted in an amended final questionnaire with improved content validity.

Fourth, the final questionnaire included 16 structured questions to rate the perception of the importance of the dimensions of the physical environment in healthcare facilities. Respondents were asked to rate their perception of an item on a 5-point scale, ranging from 1 to $5(1=$ Least important; 2 = Unimportant; 3 = Neither important nor unimportant; $4=$ Important and 5 = Very important). The questionnaire also contained an open-ended question to enable respondents to communicate their ideas on how to improve the physical environment. Demographic information such as age and gender were included. Data regarding the length of service in the hospital and weekly working hours were recorded as well.

\subsection{Study participants}

The study was conducted among healthcare providers that included doctors, nurses, technicians, and administrative/managerial staff in two Chinese hospitals in Qingdao, a coastal city in Eastern China. The hospitals were chosen for this research because of their size, reputation, world-standard facilities and the relatively large number of staff and patients. One of the hospitals is affiliated with a medical college and the other one is a general hospital, which is also the largest in the city. Combined, these two hospitals employed approximately 5900 staff and had around 4000 beds at the time of the study. Respondents were selected at random to participate in the questionnaire. All of the respondents were at least 18 years old and had worked in the respective hospitals for at least 6 months prior to the questionnaire being administered. Probationer doctors and nurses were also included in this study, in particular in the hospital affiliated with the medical college. Respondents were communicated in writing that the participation in the questionnaire was voluntary and that the confidentiality of the data would be maintained. 


\subsection{Ethical considerations}

A two-stage ethical approval was obtained for this questionnaire. In the beginning, an ethical approval was obtained from the authors’ academic institution in the UK. Furthermore, the research committees of the two participating hospitals gave approval to the study.

\subsection{Data collection}

Data for this study were collected between 12 and 26 August 2009, a time period in which there were not any special holidays in China that could create a possible bias from the use of seasonal decorations in the hospital physical environments. Two different data collection strategies were applied.

First, some of the respondents were randomly selected from each floor. In the outpatient departments, the timing for selection was between 8 am and 5 pm, Monday to Friday, which was representative of usual work practices in most departments, including outpatients. Respondents from the inpatient departments were selected during the day and evening to account for various work patterns. The researcher introduced him and the objectives of the study before handing out the questionnaires.

Second, administrative/managerial staff (e.g., head of a department) was selected during their regular meetings on Wednesday and Thursday afternoons in the two hospitals respectively. Visual aids (PowerPoint) were used to introduce the researcher and the objectives of the study to the attendees as a group, before handing out the questionnaires.

An informed consent was obtained from each participant in the study. Some of the completed questionnaires were collected as soon as they were finished, if both the respondent and the researcher happened to be available at that moment. Otherwise, the researcher went back to collect questionnaires filled in by the respondents who were occupied when they got the questionnaires.

A total of 304 members of staff from the two Chinese hospitals completed the questionnaires in full, out of the 400 distributed and the results were included in the study. The response rate was $77.3 \%$. 


\subsection{Data analysis}

Most statistical analyses have been performed with PASW Statistics version 18.0 for Windows (IBM-SPSS, 2010). Nevertheless, the researchers have carried out the test for differences in dependent correlations. Descriptive statistics on the item and scale frequencies, percentages, means and standard deviations (SD) were computed. Demographic and work related data were also analyzed descriptively by computing frequencies and percentages. Internal consistency reliability was assessed via Cronbach’s coefficient alpha (Cronbach, 1951). $\alpha \geq 0.70$ was used as the recommended value, as this study involved the comparison of groups of respondents (Nunnally \& Bernstein, 1994).

In order to reduce random sources of error and be able to assess the reliability and validity of a particular questionnaire the use of multi-item scales has been suggested by Nunnally \& Bernstein (1994). This study employed Principal Component Analysis (PCA), a mathematical technique to identify the underlying structure characterizing a set of highly correlated variables. The PCA analysis showed that fewer items in the main study had a factor loading $\geq 0.30$ in more than one factor, compared to the pilot study. The factors from the main study were easier to label and had good correspondence with other studies. Variance maximization (varimax), an orthogonal rotational strategy has been chosen for this study. PCA was performed for the 16 individual items at a significance level $p=0.001$. Three summated indices were extracted from the 16 question items of the physical environment: spatial design, environmental design and design for maintenance.

\subsection{Interviews to validate research findings}

Twelve questions were initially designed to obtain healthcare providers' perception of design factors in one of the above-mentioned hospitals. These questions evolved from the literature review, initial questionnaire findings and through discussions with members of staff at the surveyed hospitals. In order to ensure that the questions were directed, simple and specific while avoiding double-barreled questions, a senior member of staff was asked to 
answer all of the questions and give feedback for improvement. Finally, seven key questions were formulated for the interview.

Interview participants were selected from the questionnaire respondents. There was a section in the questionnaire on whether the respondent would be interested in participating in a further interview. Only nine nurses opted in, of which six were randomly selected for interview. The interview questions focused on the assessment of the perception of building design factors and their impact on healthcare providers and patients. The interviewees were informed beforehand that the interviews would be recorded and the confidentiality of the information would be maintained.

\section{Results and analysis}

\subsection{Respondents' characteristics}

Demographic and work related characteristics of the respondents are given in Table 2. Among 304 respondents, 110 (36.2\%) were male and 194 (63.8\%) were female. Almost half of the respondents (46.1\%) were aged between 26 and 35 years whereas the percentages of respondents at either end of the population were $17.1 \%$ and $3.9 \%$ for age groups $18-25$ and above 50 years respectively. At the time of the survey, $31.5 \%$ and $34.9 \%$ of the respondents had been working in respective hospitals for periods 1 to 5 , and 6 to 10 years respectively. Majority of them (72.4\%) worked between 41 and 60 hours per week while only $4.6 \%$ of the respondents worked more than 60 hours per week. The department of general surgery represented the highest number (13.8\%) of returned questionnaires. Other respondents came from the remaining 26 departments across the hospitals. The diversity of different working areas ensured that a wide range of respondents was represented in this study. A descriptive analysis of the questionnaire items is given in Table 3.

\subsection{Principal component analysis}

A principal component analysis (PCA) was conducted on the 16 questionnaire items with varimax rotation. The Kaiser-Meyer-Olkin (KMO) (Kaiser, 1974) measure verified the sampling adequacy for the analysis, $\mathrm{KMO}=0.883$, which can be considered high (Field, 
2009). Bartlett’s test of sphericity yielded a statistically significant value

( $\chi^{2}=2255.424 ; p=0.000$ ). These indices implied that the matrix was well suited for PCA.

An initial analysis was run to obtain eigenvalues for each component in the data. Three components had eigenvalues over Kaiser's criterion of 1 and in combination explained 58.4\% of the variance. Given the large sample size, the convergence of the scree plot and Kaiser's criterion on three components, this is the number of components that were retained in the final analysis. Factor loadings after rotation are given in Table 4. The PCA result suggested that components 1, 2 and 3 represented spatial design, environmental design and the design for maintenance aspects, respectively.

The reliability of each attribute was examined by Cronbach's alpha coefficient. The reliability estimates of all three components were greater than 0.70 , as shown in Table 4 , indicating a strong internal reliability among items with similar attributes. The internal consistency reliability of the overall scale was 0.901 that exceeded Nunnally's criteria, suggesting little measurement error in the instrument. According to the results, nearly half of the total variance (40.837\%) was explained by component 1 (spatial design). The rest of the variance was explained by the remaining two components.

Three of the 16 items had dual loadings on two factors. The item, 'air quality and freshness' had loadings of 0.682 and 0.408 on environmental and maintenance factors respectively. 'Cleanliness and ease of maintenance' had loadings of 0.449 and 0.522 on environmental and maintenance factors respectively. The item, 'spaciousness of working areas' had loadings of 0.475 and 0.487 on spatial and maintenance factors respectively. To investigate further, Cronbach's $\alpha$, if the item was deleted, was examined for each item. The value for $\alpha$ decreased if any of the items were deleted, except for 'cleanliness and ease of maintenance'. The increase in Cronbach's $\alpha$ for 'cleanliness and ease of maintenance' was marginal $(0.902-0.901=0.001)$. On the other hand, with a mean score of 4.66 out of 5.00, cleanliness was ranked as very important by the respondents. Considering the above, the 3 factor solution was retained along with the original loadings of the items. 
3.3. Relationship between personal information and perception of design factors

Before investigating the relationship between respondent characteristics and perception of design factors, respondents were regrouped to simplify data analysis and interpretation. A small number of staff worked less than 20 hours per week; therefore, the variable 'working hours' was rescaled to have the ranges: less than 40 hours, between 40 and 60 hours and longer than 60 hours. The rescaled 'working hours' variable corresponded to short, medium and long periods of working time. Similarly, the variable 'age' was re-categorized to indicate the ranges: young (18-35 years), middle aged (36-50 years) and senior staff (older than 50 years). To investigate the effect of job roles, the respondents were categorized into two groups: administrative/managerial and physicians/nurses/technicians.

The distribution of the data was not normal; hence, non-parametric tests were carried out on 16 questionnaire items and reported in Table 5. Mann-Whitney $U$-test was carried out on 'gender' and 'role', whereas Kruskal-Wallis test was carried out on 'age', 'working hours' and 'length of service'. Results show that there is a significant difference in perception between male and female healthcare providers for items: cleanliness and ease of maintenance; air quality and freshness; noise level; and provision for hand hygiene. Age has a significant effect on the perception of the following design factors: noise level; spaciousness; location and orientation of the space; and architectural design of the space.

The perception of the factors: thermal comfort, proximity to wards, adequate illumination, availability of daylight and spaciousness is significantly influenced by working hours per week. This translates to 5 out of 9 items in components 2 and 3, demonstrating the importance of the number of hours worked per week on perceptions of maintenance and environmental design factors.

There is also a significant difference in the perception of factors: indoor plants, interior/exterior landscaping; furniture layout; and proximity to wards between different groups of respondents, based on their length of service. The design factor, proximity to wards has a high level of significance, $p<0.001$.

No significant difference in perception was found due to respondents' job roles. 


\section{Discussion}

\subsection{Perception of design factors}

Healthcare providers are key stakeholders and critically important informants in the process of design and refurbishment of healthcare facilities. Their perception of physical environment features are based on their observation of and interaction with hospital spaces over their working life. All of the 16 investigated design aspects were ranked relatively high with mean scores ranging between 3.36 and 4.66, from the lowest to the highest, on a scale of 1 to 5 . Overall, 'cleanliness and ease of maintenance' was considered to be very important and had the highest mean score (= 4.66) and lowest standard deviation (=0.522). The item, 'presence of coordinated art objects' was considered to be the least important of the analyzed design aspects. In terms of constructed dimensions, the respondents appear to be more concerned about the environmental and maintenance design factors, compared to spatial design. This is evident in Table 3, where all of the nine items under environmental and maintenance design dimensions topped the list with a minimum mean score of 4.00 .

The overall findings agree with conventional wisdom and results from past research on quality of care and user satisfaction, the closely aligned topics of research to the present study. Cleanliness is routinely reported in literature as one of the most important attributes of a healthcare environment and has the potential to influence care quality and staff and patient wellbeing. Although, there exists a greater need for cleanliness in departments such as surgery, emergency and intensive care units where patients are more vulnerable to the risk of infection (Lavy \& Dixit, 2010), it is also important in lower risk areas such as care homes. In a review of service users' expectations of inpatient mental health care, Hopkins et al. (2009) identified cleanliness as an important aspect along with comfort. In a recent article, Dancer (2011) noted the emergence of evidence on the importance of the clinical environment in encouraging hospital infection. Given the wide-ranging surfaces, equipment and building design, the article argued for a tailored approach towards cleanliness. Cleanliness in the hospital environment has also been linked with the recruitment, retention and performance of nurses in the UK National Health Service (NHS) (PwC, 2004). 
In terms of mean response scores, 'air quality and freshness' was ranked as the second most important item. Air quality has previously been associated with user satisfaction (PwC, 2004), staff performance (Seppänen et al., 2006) and the prevention of nosocomial infections among staff and patients (Leung \& Chan, 2006). Gosden et al. (1998) discussed the importance of air quality in infection control by citing examples of how small numbers of organisms could cause orthopedic implant infections, giving rise to a considerable degree of morbidity and mortality. Leung \& Chan (2006) noted that parameters of indoor air quality (IAQ) were well understood in commercial and public buildings and how these could adversely affect occupant health, with conditions ranging from sick building syndrome (SBS) to building related illnesses (BRI) such as pneumonitis and cancers. IAQ, to a large extent, depends on the rate of outdoor/fresh airflow, a higher rate of which is more efficient in diluting the concentration of odor and volatile organic compounds (VOC). In a review of published sources that investigated the link between ventilation rates and staff performance, Seppänen et al. (2006) noted that in all of the reviewed cases higher ventilation rates resulted in higher performance.

The respondents have rated 'Noise level' as the third most important design aspect. The impact of noise pollution on both the patient and healthcare providers has been extensively studied in critical care units and other healthcare areas. Patients' wellbeing and their health outcomes are found to be affected by higher levels of noise because of poor sleep quality (Freedman et al., 1999) and increased stress. In the case of healthcare providers, noise pollution increases the probability of errors and is one of the risk factors for provider burnout (Tijunelis et al., 2005). It is widely acknowledged that sound levels higher than $55 \mathrm{dBA}$ brings disturbing effect (Beranek, 1971). The Environmental Protection Agency (EPA) in the United States recommends that the ambient noise level in a hospital should not exceed $40 \mathrm{~dB}$. However, many studies suggest that this recommended threshold of ambient sound is routinely exceeded (Busch-Vishniac et al., 2005; Souter \& Wilson, 1986).

'Thermal comfort' is considered by the respondents to be the fourth most important aspect. The sensation of comfort is dependent on many physical and psycho-physiological 
variables such as indoor air temperature, metabolism, clothing insulation, ability to modify/control the indoor environment, etc. (De Dear, 2004). The effect of physical environment aspects on thermal comfort is more pronounced for naturally ventilated buildings, compared to fully air-conditioned buildings. Thermal comfort is also indirectly linked with indoor air quality in the sense that increased ventilation helps in diluting odor and VOC, as well as in bringing down indoor temperatures to a comfortable level.

The order of importance of the remaining environmental and maintenance design factors is as follows: 'proximity to wards', 'provision for hand hygiene', 'adequate illumination', 'availability of daylight' and 'spaciousness'. All of the architectural design aspects were ranked lower than environmental and maintenance design aspects, with mean scores ranging from 3.36 for 'presence of coordinated art objects' to 3.85 for 'location and orientation of the space'. The fact that mean scores for all spatial design aspects were lower than 4.00 indicates that the respondents considered them to be important but not as important as environmental and maintenance design factors. Aspects related to various environmental stimuli such as art objects, indoor plants and interior/exterior landscaping were considered to be of low importance, as shown in Table 3. The effect of such stimuli on staff and patient wellbeing and patient recovery has been found to be positive in past research (Dijkstra et al., 2006; Golden et al., 2005; Ulrich, 1984; Ulrich et al., 2004). However, their relatively low ranking in this research may be due to the fact that previous research looked at individual aspects, rather than the integrated whole, as is the case in this research. Another reason may be that the respondents did not make a strong connection between abstract environmental stimuli and staff performance and/or patient outcomes. Further research is, therefore, necessary to investigate the low mean scores of spatial design aspects.

\subsection{Perception and demographic characteristics}

Of the four demographic and work related variables investigated in detail in this study, working hours per week explained significant differences in perception of several of the maintenance and environmental design factors. Women were found to be more perceptive of 
sense-sensitive (Mazuch, 2005) design factors such as the ones related to five senses: smell, taste, sight, feel and hearing. Mean scores by female staff were higher than their male counterparts on cleanliness and ease of maintenance (mean score of 4.71 vs. 4.56); indoor air quality and freshness (4.44 vs. 4.30); noise level (4.40 vs. 4.23); and provision for hand hygiene (4.27 vs. 4.05). This result is in accordance with previous research, which indicated that females showed greater sensitivity and/or physiologic responsiveness to stimuli in a number of sensory modalities, in particular in olfactory sensitivities, than males (Velle, 1987). Women are also reported to suffer from sick building syndrome (SBS) more often than men (Brasche et al., 2001). In Chinese culture, women take more responsibility for environmental cleanliness at home, which may account for and translate into them having a higher expectation of cleanliness than men. In other words, females expect cleaner and quieter environments to focus on work. Nursing stations and patient rooms are their primary working locations where a minimum level of noise and better air quality and freshness are highly demanded. All six interviewed nurses expressed their preference for design for cleanliness that eliminates clutter and helps them care for patients more effectively.

In addition, the research has identified different perceptions of design factors between respondents who worked less than or equal to 40 hours a week $\left(N_{\leq 40}=220\right)$ than the staff who worked more hours per week $\left(N_{41-60}=70\right.$ and $\left.N_{>60}=14\right)$. Respondents working less than or equal to 40 hours represent the working pattern of the majority of the staff in the two hospitals. They considered 10 out 16 investigated design factors to be more important than the other groups. The 10 design factors came from all three principal components: spatial, maintenance and environmental design and included both the highly ranked ones (e.g., proximity to wards) as well as the factors with low mean scores (e.g., presence of coordinated art objects). In comparison, respondents who worked 41-60 hours per week considered the following design factors to be more important than the others: cleanliness and ease of maintenance (mean score of 4.68); Noise level (4.35); Adequate illumination (4.18); Pleasant color scheme (3.7); Indoor plants, interior/exterior landscaping (3.55) and Furniture layout 
(3.54). Exterior view from the space had an equal mean score of 3.68 from the respondents who worked less than or equal to 40 hours per week and the respondents who worked between 41 and 60 hours per week. Findings related to 'working hours' can be used for designing departments with varying work patterns; e.g., inpatients vs. outpatients.

Among the spatial design factors, 'location and orientation of a space’ was rated higher by the respondents than most of the other factors in the category. This may be due to the cultural preference of the Chinese for coordinated location and orientation of a space and furniture within. Evidence of locational preference can be seen in the ancient Chinese wisdom called Feng Shui, which was based on the observation of astronomical phenomena, natural phenomena and human behavior (Mak \& Ng, 2005). These three aspects were combined with Chinese astronomy, geography and philosophy to devise rules for the design of spaces, buildings and cities. Interviewed nurses also stated their preferences for a better orientation of the space they worked in. Some of the comments in the returned questionnaires also support this finding; e.g., one responded commented “...[I] prefer to work in a south-faced room with more natural light...”.

Nurses described their preferences for the design of nursing stations in both the questionnaire and interview. They noted that the design of nursing stations could be such that there was a degree of acoustic separation between their working areas and adjoining corridors and patient areas. In essence, they referred to the ambient noise level, which could be brought down through careful design. The preference for better acoustic design was mentioned often by nurses working in departments such as accident and emergency where there were increased interactions with patients and families. This is an interesting finding, which illustrates the multi-dimensional and multi-objective nature of architectural design. From a spatial design perspective, visual and auditory links need to be maintained between nursing stations and patient areas for effective care delivery, which may contribute to an increased noise level. At the same time, staff working in these areas needs a quiet space to concentrate on work. The use of hard surfaces (for easy cleaning and better control of infection) adds to this problem as they reflect sound and, therefore, contribute to the ambient noise level. The 
'push and pull' between the aforementioned design objectives: efficient care delivery, reduction of noise and cleanliness serve to illustrate the challenges in design decision making.

\subsection{Integrating user perception in healthcare facility design}

One of the advantages of research focusing on physical environments is that findings can be applied more easily in evidence-based design decision-making. Indices of factors and their relative ranking can be identified based on user characteristics and use patterns of the space. The indices can then be used for prioritizing design factors for heuristics based decisionmaking, typically found in early design stages. However, with the increase in the number of design variables (i.e., factors or aspects) and goals, the reconciliation between conflicts becomes complicated, rendering the conventional 'cognitive' and 'trial and error' approach inefficient for effective decision-making (Mourshed, 2006). To overcome the limitations of cognitive or heuristics based approaches, design automation such as numerical optimization (Caldas, 2008; Mourshed et al., 2011) can be applied where the indices of design factors and their relative ranking are converted into proportional weights on design goals and the solution space is searched algorithmically.

\section{Limitations}

Certain limitations of this study need to be pointed out. The questionnaire was conducted in two Chinese hospitals in Qingdao, a major city in Shandong province in Eastern China. The responses are, therefore, inherently the Chinese healthcare providers' perception of design factors and their relative importance. However, the differences in perception between respondents from China and the rest of the world may be minimal, in particular for universal design factors that are not culturally significant; e.g. adequate illumination and daylight availability. Factors related to building services and systems such as thermal comfort is another example of such variable. This may be due to the fact that the design and operation of major healthcare facilities such as general or medical college hospitals are more universal than other types of buildings. Also, there is evidence that contemporary developments in Chinese architecture, in particular in urban areas, have had considerable influences from 
globalization (Ren, 2008) and in a sense western architectonic philosophies during the second half of the 20th century. The end product was rather a universal urban fabric, with little difference in spatial organization and manifestation of form and space between urban buildings in China and the rest of the world. The contextual bias from buildings themselves may, therefore, be low.

Further research may be needed for universal applications of some of the research findings. For example, the relationship between working hours and perception may be affected by average hours worked per week by healthcare providers in a country. Chinese healthcare workers typically worked more hours per week than their counterparts in the West: e.g., American physicians worked 53.9 hr (Dorsey et al., 2003) while their Taiwanese counterparts worked $65.6 \mathrm{hr}$ per week (Chen et al., 2010). Therefore, the effect of work pattern may be different, the detailed understanding of which requires further research. Another aspect of the study is the proportion of female respondents (63.8\%), which may appear high but is demographically representative of healthcare staff in China and the rest of the world. Female nurses make up the majority of the healthcare workforce, which reflects a traditional career trend in healthcare labor markets in most countries (Zurn et al., 2002). Although the research did not find significant differences in perception between administrators and managers vs. physicians and nurses; i.e., non-medical vs. medical - there may be differences between sub-categories.

\section{Conclusion}

Past research on physical environments in hospitals focused mostly on user satisfaction, linked with service delivery in a specific setting. Research on satisfaction typically explored users' (staff and patients) perception of the quality of care and analyzed the impact of some tangible dimensions such as salary, work pattern, presence/absence of certain facilities, etc. Findings from such research are convenient for use in financial and efficiency related strategic planning and management. They seldom provide useful insights into facility design aspects that are critical for creating a therapeutic environment. 
Using a 16-item structured questionnaire, this research explored healthcare providers’ perception of design aspects related to physical environments in hospitals. Aspects related to the design for maintenance were perceived to be more important by healthcare providers than those related to spatial design. Environmental design aspects related to sensory perceptions were also ranked as very important by the respondents. There were significant differences in perception of the body-contact and sensory aspects among males and females. Of other demographic and work related variables, the length of service had an effect on spatial design aspects such as landscaping and indoor plants that had an indirect association with the healing environment. Working pattern; i.e., 'hours worked per week' had significant associations with the perception of maintenance and environmental design aspects.

In addition to contributing to the growing body of knowledge on users' perception of physical environment aspects, this paper shed light on the use of the findings in architectural design. 


\section{References}

Aiken, L. H., Sloane, D. M., Clarke, S., Poghosyan, L., Cho, E., You, L., Finlayson, M., Kanai-Pak, M., \& Aungsuroch, Y. (2011). Importance of work environments on hospital outcomes in nine countries. International Journal for Quality in Health Care, 23, 357-364.

Alimoglu, M. K., \& Donmez, L. (2005). Daylight exposure and the other predictors of burnout among nurses in a University Hospital. International Journal of Nursing Studies, 42, 549-555.

Bayo, M. V., García, A. M., \& García, A. (1995). Noise levels in an urban hospital and workers’ subjective responses. Archives of Environmental Health, 50, 247-251.

Beranek, L. (1971). Noise and Vibration Control. New York: McGraw Hill.

Brasche, S., Bullinger, M., Morfeld, M., Gebhardt, H. J., \& Bischof,W. (2001). Why do women suffer from sick building syndrome more often than men? - Subjective higher sensitivity versus objective causes. Indoor Air, 11, 217-222.

Buchanan, T. L., Barker, K. N., Gibson, J. T., Jiang, B. C., \& Pearson, R. E. (1991). Illumination and errors in dispensing. American Journal of Hospital Pharmacy, 48, 2137-2145.

Busch-Vishniac, I., West, J., Barnhill, C., Hunter, T., Orellana, D., \& Chivukula, R. (2005). Noise levels in Johns Hopkins Hospital. Journal of the Acoustical Society of America, 118, 3629-3645.

Caldas, L. (2008). Generation of energy-efficient architecture solutions applying GENE_ARCH: An evolution-based generative design system. Advanced Engineering Informatics, 22, 59-70.

Chen, H., Lee, C., \& Chang, R. (2010). Workload of attending physicians at an academic center in Taiwan. Journal of the Chinese Medical Association, 73, 425-430.

Cronbach, L. J. (1951). Coefficient alpha and the internal structure of tests. Psychometrika, 16, 297334.

Crow, R., Gage, H., Hampson, S., Hart, J., Kimber, A., Storey, L., \& Thomas, H. (2002). The measurement of satisfaction with healthcare: Implications for practice from a systematic review of the literature. Health Technology Assessment, 6, 1-244.

Cummings, G. G., MacGregor, T., Davey, M., Lee, H., Wong, C. A., Lo, E., Muise, M., \& Stafford, E. (2010). Leadership styles and outcome patterns for the nursing workforce and work environment: A systematic review. International Journal of Nursing Studies, 47, 363-385.

Dalke, H., Little, J., Niemann, E., Camgoz, N., Steadman, G., Hill, S., \& Stott, L. (2006). Colour and lighting in hospital design. Optics \& Laser Technology, 38, 343-365.

Dancer, S. J. (2011). Hospital cleaning in the 21st century. European Journal of Clinical Microbiology \& Infectious Diseases, 30, 1473-1481.

De Dear, R. (2004). Thermal comfort in practice. Indoor Air, 14, 32-39.

Devlin, A. S., \& Arneill, A. B. (2003). Health care environments and patient outcomes. Environment and Behavior, 35, 665-694.

Dijkstra, K., Pieterse, M., \& Pruyn, A. (2006). Physical environmental stimuli that turn healthcare facilities into healing environments through psychologically mediated effects: Systematic review. Journal of Advanced Nursing, 56, 166-181.

Dinç, P. (2009). Gender (in)difference in private offices: A holistic approach for assessing satisfaction and personalization. Journal of Environmental Psychology, 29, 53-62.

Dorsey, E. R., Jarjoura, D., \& Rutecki, G. W. (2003). Influence of controllable lifestyle on recent trends in specialty choice by US medical students. The Journal of the American Medical Association, 290, $1173-1178$.

Dubbs, D. (2004). Sound effects: Design and operations solutions to hospital noise. Health Facilities Management, 17, 14-18.

Field, A. (2009). Discovering statistics using SPSS. London: SAGE Publications Ltd. 
Fischer, F. M., Borges, F. N., Rotenberg, L., Latorre, M., Soares, N. S., Rosa, P. L., Teixeira, L. R., Nagai, R., Steluti, J., \& Landsbergis, P. (2006). Work ability of health care shift workers: What matters? Chronobiology International, 23, 1165-1179.

Freedman, N. S., Kotzer, N., \& Schwab, R. J. (1999). Patient perception of sleep quality and etiology of sleep disruption in the intensive care unit. American Journal of Respiratory and Critical Care Medicine, 159, 1155-1162.

Garrett, L., Chowdhury, A. M. R., \& Pablos-Méndez, A. (2009). All for universal health coverage. Lancet, 374, 1294-1299.

Gesler, W., Bell, M., Curtis, S., Hubbard, P., \& Francis, S. (2004). Therapy by design: Evaluating the UK hospital building program. Health \& Place, 10, 117-128.

Golden, R. N., Gaynes, B. N., Ekstrom, R. D., Hamer, R. M., Jacobsen, F. M., Suppes, T.,Wisner, K. L., \& Nemeroff, C. B. (2005). The efficacy of light therapy in the treatment of mood disorders: A review and meta-analysis of the evidence. American Journal of Psychiatry, 162, 656-662.

Gosden, P., MacGowan, A., \& Bannister, G. (1998). Importance of air quality and related factors in the prevention of infection in orthopaedic implant surgery. Journal of Hospital Infection, 39, 173 - 180.

Guenther, R., \& Vittori, G. (2008). Sustainable healthcare architecture. New Jersey: John Wiley and Sons.

Hayes, L. J., O’Brien-Pallas, L., Duffield, C., Shamian, J., Buchan, J., Hughes, F., Spence Laschinger, H. K., North, N., \& Stone, P. W. (2006). Nurse turnover: A literature review. International Journal of Nursing Studies, 43, 237-263.

Hopkins, J. E., Loeb, S. J., \& Fick, D. M. (2009). Beyond satisfaction, what service users expect of inpatient mental health care: A literature review. Journal of Psychiatric and Mental Health Nursing, 16, 927-937.

IBM-SPSS (2010). Predictive Analytics Software (PASW) Statistics [computer software]. Somers: International Business Machines (IBM) SPSS.

Jones, C. B. (2005). Nurse turnover: Why it is such a tough problem to solve? Nurse Leader, 3, 43-47.

Kaiser, H. F. (1974). An index of factorial simplicity. Psychometrika, 39, 31-36.

Lankford, M., Zembower, T., Trick,W., Hacek, D., Noskin, G., \& Peterson, L. (2003). Influence of role models and hospital design on hand hygiene of healthcare workers. Emerging Infectious Disease, 9, 217-23.

Lavy, S., \& Dixit, M. (2010). Facility managers’ preferred interior wall finishes in acute-care hospital buildings. In Proceedings of the 2010 CIB World Congress - Building a Better World. Salford, UK: Conseil International du Bâtiment.

Leung, M., \& Chan, A. (2006). Control and management of hospital indoor air quality. Medical Science Monitor, 12, SR17-23.

Mak, M. Y., \& Ng, S. T. (2005). The art and science of Feng Shui: A study on architects’ perception. Building and Environment, 40, 427-434.

Mazuch, S. (2005). Creating healing environments: Humanistic architecture and therapeutic design. Journal of Public Mental Health, 4, 48-52.

Mourshed, M. (2006). Interoperability-based optimisation of architectural design. Unpublished doctoral dissertation, National University of Ireland, Cork.

Mourshed, M., Shikder, S., \& Price, A. D. F. (2011). Phi-array: A novel method for fitness visualization and decision making in evolutionary design optimization. Advanced Engineering Informatics, 25, 676-687.

Nunnally, J., \& Bernstein, I. (1994). Psychometric Theory. (3rd ed.). New York: McGraw-Hill.

O’Neill, M. J. (1994). Work space adjustability, storage, and enclosure as predictors of employee reactions and performance. Environment and Behavior, 26, 504 -526. 
Pittet, D., Hugonnet, S., Harbarth, S., Mourouga, P., Sauvan, V., Touveneau, S., \& Perneger, T. V. (2000). Effectiveness of a hospital-wide programme to improve compliance with hand hygiene. Lancet, 356, 1307-1312.

Prasad, S. (2008). Changing hospital architecture. London: RIBA Publishing.

PwC (2004). The role of hospital design in the recruitment, retention and performance of NHS nurses in England. London: CABE and PricewaterhouseCoopers LLP.

Reiling, J. (2007). Safe by design: Designing safety in health care facilities, processes, and culture. Oakbrook Terrace: Joint Commission Resources.

Ren, X. (2008). Architecture and nation building in the age of globalization: Construction of the national stadium of Beijing for the 2008 Olympics. Journal of Urban Affairs, 30, 175-190.

Rollins, J. A. (2004). Evidence-based hospital design improves health care outcomes for patients, families, and staff. Pediatric Nursing, 30, 338-339.

Roseman, C., \& Booker, J. M. (1995). Workload and environmental factors in hospital medication errors. Nursing Research, 44, 226-230.

Seppänen, O., Fisk, W. J., \& Lei, Q. H. (2006). Ventilation and performance in office work. Indoor Air, $16,28-36$.

Shikder, S., Mourshed, M., \& Price, A. (2011). Therapeutic lighting design for the elderly: A review. Perspectives in Public Health, DOI: 10.1177/1757913911422288.

Sime, J. D. (1986). Creating places or designing spaces? Journal of Environmental Psychology, 6, 4963.

Souter, R., \& Wilson, J. (1986). Does hospital noise disturb patients? British Medical Journal, 292, 305.

Stamps III, A. E. (2007). Evaluating spaciousness in static and dynamic media. Design Studies, 28, 535-557.

Stuckey, H. L., \& Nobel, J. (2010). The connection between art, healing, and public health: A review of current literature. American Journal of Public Health, 100, 254-263.

Tijunelis, M. A., Fitzsullivan, E., \& Henderson, S. O. (2005). Noise in the ED. American Journal of Emergency Medicine, 23, 332 - 335.

Trinkoff, A. M., Johantgen, M., Muntaner, C., \& Le, R. (2005). Staffing and worker injury in nursing homes. American Journal of Public Health, 95, 1220-1225.

Tzeng, H., \& Yin, C. (2009). Perspectives of recently discharged patients on hospital fall-prevention programs. Journal of Nursing Care Quality, 24, 42-49.

Ulrich, R. (1984). View through a window may influence recovery from surgery. Science, 224, 420421.

Ulrich, R., Zimring, C., Quan, X., Joseph, A., \& Choudhary, R. (2004). The Role of the physical environment in the hospital of the 21st century: A Once-in-a-lifetime opportunity. Martinez: The Center for Health Design.

Ulrich, R. S. (1999). Effects of gardens on health outcomes: Theory and research. In Healing Gardens: Therapeutic Benefits and Design Recommendations (pp. 27-86). New York: John Wiley \& Sons.

Ulrich, R. S., Zimring, C., Zhu, X., DuBose, J., Seo, H., Choi, Y., Quan, X., \& Joseph, A. (2008). A review of the research literature on evidence-based healthcare design (part I). Health Environments Research and Design, 1, 61-125.

Velle, W. (1987). Sex differences in sensory functions. Perspectives in Biology and Medicine, 30, 490522.

Vischer, J. C. (2007). The effects of the physical environment on job performance: Towards a theoretical model of workspace stress. Stress and Health, 23, 175-184.

Whitehouse, S., Varni, J. W., Seid, M., Cooper-Marcus, C., Ensberg, M. J., Jacobs, J. R., \& Mehlenbeck, R. S. (2001). Evaluating a children's hospital garden environment: Utilization and consumer satisfaction. Journal of Environmental Psychology, 21, 301-314. 
WHO (2002). Prevention of hospital-acquired infections. Geneva: World Health Organization.

Witterseh, T., Wyon, D. P., \& Clausen, G. (2004). The effects of moderate heat stress and open-plan office noise distraction on SBS symptoms and on the performance of office work. Indoor Air, 14, 30-40.

Woodring, S., Polomano, R. C., Haagen, B., Haack, M., Nunn, R. R., Miller, G. L., Zarefoss, M. A., \& Tan, T. L. (2004). Development and testing of patient satisfaction measure for inpatient psychiatry care. Journal of Nursing Care Quality, 19, 137-148.

Zimring, C. (1990). The cost of confusion: Non-monetary and monetary cost of the Emory University hospital wayfinding system. Atlanta: Georgia Institute of Technology.

Zurn, P., Poz, M. D., Stilwell, B., \& Adams, O. (2002). Imbalances in the health workforce. Geneva: World Health Organization. 
Table 1: Design factors identified from the literature review.

\begin{tabular}{|c|c|}
\hline Design factor & Impact \\
\hline $\begin{array}{l}\text { Adequate } \\
\text { illumination }\end{array}$ & $\begin{array}{l}\text { Adequate illumination, artificial and natural lighting combined, is required to perform visual } \\
\text { tasks (Shikder et al., 2011). Adequate illumination on work surfaces lowers rates of } \\
\text { medication-dispensing errors (Buchanan et al., 1991). }\end{array}$ \\
\hline $\begin{array}{l}\text { Air quality and } \\
\text { freshness }\end{array}$ & $\begin{array}{l}\text { Defined as the absence of unpleasant smell. Poor and insufficient ventilation decreases work } \\
\text { efficiency and productivity (Seppänen et al., 2006). Poor air quality increases the risk of } \\
\text { nosocomial infection (WHO, 2002). }\end{array}$ \\
\hline $\begin{array}{l}\text { Architectural } \\
\text { design of the space }\end{array}$ & $\begin{array}{l}\text { Architectural design of a space is more than just the geometric organization; it influences } \\
\text { users’ sensory perceptions. Spatial architectural designs affect staff recruitment and } \\
\text { retention, as well as efficiency and productivity (Guenther \& Vittori, 2008). }\end{array}$ \\
\hline $\begin{array}{l}\text { Availability of } \\
\text { daylight }\end{array}$ & $\begin{array}{l}\text { Light, especially daylight impacts on visual performance and psychological state of a person } \\
\text { by regulating the circadian rhythm. It impacts on patient outcome, as well as provide } \\
\text { restorative benefits to medical staff and office workers (Ulrich et al., 2008). The lack of } \\
\text { daylight has also been associated with job burnout (Alimoglu \& Donmez, 2005) and } \\
\text { medication errors (Roseman \& Booker, 1995). }\end{array}$ \\
\hline $\begin{array}{l}\text { Cleanliness and } \\
\text { ease of } \\
\text { maintenance }\end{array}$ & $\begin{array}{l}\text { The design of the building and constituent spaces are linked with cleanliness (PwC, 2004). } \\
\text { Surface characteristics affect infection control (Dancer, 2011). }\end{array}$ \\
\hline $\begin{array}{l}\text { Exterior view from } \\
\text { the space }\end{array}$ & $\begin{array}{l}\text { Views to the outside are manifested as positive emotional and physiological changes } \\
\text { leading to stress reduction or restorative benefits (Ulrich, 1984). }\end{array}$ \\
\hline Furniture layout & $\begin{array}{l}\text { Ergonomic characteristics of furniture and equipment can cause long-term muscular or } \\
\text { nerve injury due to poor bodily positioning or muscle use (Vischer, 2007). Furniture layout } \\
\text { has been identified as the primary concern for patient falls (Tzeng \& Yin, 2009). }\end{array}$ \\
\hline $\begin{array}{l}\text { Indoor plants and } \\
\text { landscaping }\end{array}$ & $\begin{array}{l}\text { Contribute to positive distraction and a pleasant working environment. Views of natural } \\
\text { settings are found to influence patient recovery (Ulrich, 1999). }\end{array}$ \\
\hline $\begin{array}{l}\text { Location and } \\
\text { orientation of the } \\
\text { space }\end{array}$ & $\begin{array}{l}\text { Linked with site specific thermal, visual, auditory and olfactory environments. In terms of } \\
\text { physical settings, poor location and orientation of a space may result in a poor wayfinding } \\
\text { system and may contribute to increased staff stress and time wastage } \\
\text { (Zimring, 1990). }\end{array}$ \\
\hline Noise level & $\begin{array}{l}\text { The level of ambient noise has strong links with patient outcomes. Staff effectiveness } \\
\text { increase in quiet settings (Dubbs, 2004). Healthcare providers perceive higher noise levels } \\
\text { as stressful and sufficiently high to interfere with their work (Bayo et al., 1995). }\end{array}$ \\
\hline $\begin{array}{l}\text { Pleasant color } \\
\text { scheme }\end{array}$ & $\begin{array}{l}\text { Color, an inherent property of all materials and surfaces, is considered an inseparable } \\
\text { element of design. Together with lighting, color has an impact on people's responses to the } \\
\text { environment and affect staff morale and quality of healthcare (Dalke et al., 2006). }\end{array}$ \\
\hline $\begin{array}{l}\text { Presence of } \\
\text { coordinated art } \\
\text { objects }\end{array}$ & $\begin{array}{l}\text { Art-based interventions are found to be effective in reducing adverse physiological and } \\
\text { psychological outcomes (Stuckey \& Nobel, 2010). There is potential to enhance staff morale } \\
\text { and satisfaction by integrating them in arts initiatives that have a positive healing effect on } \\
\text { patients. However, Ulrich et al. (2004) found that not all art was suitable for healthcare } \\
\text { spaces. }\end{array}$ \\
\hline Proximity to wards & $\begin{array}{l}\text { Long distances between different working areas have a negative impact on nursing } \\
\text { performance (PwC, 2004) and quality of care. }\end{array}$ \\
\hline $\begin{array}{l}\text { Provision for hand } \\
\text { hygiene }\end{array}$ & $\begin{array}{l}\text { Hands of healthcare staff are the principal cause of nosocomial or hospital acquired } \\
\text { infection (HAI) (Pittet et al., 2000). The lack of hand hygiene provisions such as availability } \\
\text { of washbasins is perceived as a factor contributing to HAI (Lankford et al., 2003). }\end{array}$ \\
\hline Spaciousness & $\begin{array}{l}\text { The lack of spaciousness has been seen as a strong ambient stressor (Stamps III, 2007). } \\
\text { Perception of room spaciousness has effects on user satisfaction and performance (O’Neill, } \\
\text { 1994). }\end{array}$ \\
\hline Thermal comfort & $\begin{array}{l}\text { Thermal discomfort is associated with inadequate work ability among nurses (Fischer et al., } \\
\text { 2006) and decreased productivity by influencing their ability to think (Witterseh et al., } \\
\text { 2004). }\end{array}$ \\
\hline
\end{tabular}


Table 2: Background information of the respondents.

\begin{tabular}{|c|c|c|c|}
\hline Variable & Scale/category & $N$ & $\%$ \\
\hline \multirow[t]{4}{*}{ Age (yr) } & $18-25$ & 52 & 17.1 \\
\hline & $26-35$ & 140 & 46.1 \\
\hline & $36-50$ & 100 & 32.9 \\
\hline & $>50$ & 12 & 3.9 \\
\hline \multirow[t]{2}{*}{ Gender (-) } & Male & 110 & 36.2 \\
\hline & Female & 194 & 63.8 \\
\hline \multirow{4}{*}{$\begin{array}{l}\text { Working } \\
\text { hour (hr) }\end{array}$} & $<20$ & 2 & 0.7 \\
\hline & $20-40$ & 68 & 22.3 \\
\hline & $41-60$ & 220 & 72.4 \\
\hline & $>60$ & 14 & 4.6 \\
\hline \multirow{4}{*}{$\begin{array}{l}\text { Length of } \\
\text { service (yr) }\end{array}$} & $<1$ & 33 & 10.9 \\
\hline & $1-5$ & 96 & 31.5 \\
\hline & $6-10$ & 106 & 34.9 \\
\hline & $>10$ & 69 & 22.7 \\
\hline \multirow[t]{27}{*}{ Department } & Accident and emergency & 14 & 4.6 \\
\hline & Administration & 35 & 11.5 \\
\hline & Burns & 5 & 1.6 \\
\hline & Cardiac & 17 & 5.6 \\
\hline & Chest surgery & 9 & 3 \\
\hline & Chinese medicine & 6 & 2 \\
\hline & Clinical pharmacology & 12 & 3.9 \\
\hline & Critical care (ICU/HDU) & 10 & 3.3 \\
\hline & Dermatology & 3 & 1 \\
\hline & Elderly care & 2 & 0.7 \\
\hline & Gastrointestinal & 11 & 3.6 \\
\hline & General surgery & 42 & 13.8 \\
\hline & Hematology & 15 & 4.9 \\
\hline & Hepatology & 6 & 2 \\
\hline & Incretion & 1 & 0.3 \\
\hline & Infectious diseases & 3 & 1 \\
\hline & Management & 12 & 3.9 \\
\hline & Midwifery & 11 & 3.6 \\
\hline & Neurosurgery/neurology & 6 & 2 \\
\hline & Operating theaters & 6 & 2 \\
\hline & Orthopedics & 17 & 5.6 \\
\hline & Ophthalmology & 3 & 1 \\
\hline & Pediatrics/ neonatal & 4 & 1.3 \\
\hline & Respiratory & 24 & 7.9 \\
\hline & Stomatology & 2 & 0.7 \\
\hline & Urology & 14 & 4.6 \\
\hline & X-Ray/pathology & 14 & 4.6 \\
\hline
\end{tabular}


Table 3: Descriptive analysis.

\begin{tabular}{|c|c|c|c|c|c|c|c|}
\hline \multirow[t]{2}{*}{ Item } & \multicolumn{5}{|c|}{ Response $^{*}(\%)$} & \multirow[t]{2}{*}{ Mean } & \multirow[t]{2}{*}{ SD } \\
\hline & 1 & 2 & 3 & 4 & 5 & & \\
\hline Cleanliness and ease of maintenance & 0 & 0 & 2.3 & 29.6 & 68.1 & 4.66 & 0.522 \\
\hline Air quality and freshness ${ }^{\dagger}$ & 0.3 & 0.7 & 6.3 & 45.4 & 47.4 & 4.39 & 0.666 \\
\hline Noise level & 0.3 & 1 & 9.2 & 43.4 & 46.1 & 4.34 & 0.713 \\
\hline Thermal comfort & 0 & 1 & 10.2 & 48 & 40.8 & 4.29 & 0.685 \\
\hline Proximity to wards & 0 & 1.6 & 9.9 & 46.7 & 41.8 & 4.29 & 0.709 \\
\hline Provision for hand hygiene & 0 & 3.3 & 10.9 & 49 & 36.8 & 4.19 & 0.757 \\
\hline Adequate illumination ${ }^{\ddagger}$ & 0 & 0.7 & 13.2 & 55.6 & 30.6 & 4.16 & 0.663 \\
\hline Availability of daylight & 0 & 1 & 17.1 & 57.2 & 24.7 & 4.06 & 0.675 \\
\hline Spaciousness & 1.1 & 1.1 & 20.4 & 52 & 25.7 & 4 & 0.769 \\
\hline Location and orientation of the space & 0.3 & 2.6 & 27 & 51.6 & 18.4 & 3.85 & 0.754 \\
\hline Architectural design of the space & 0 & 5.3 & 27.3 & 50 & 17.4 & 3.8 & 0.786 \\
\hline Pleasant color scheme & 0 & 5.3 & 33.6 & 48.7 & 12.5 & 3.68 & 0.757 \\
\hline Exterior view from the space & 1.3 & 4.9 & 32.2 & 49.3 & 12.2 & 3.66 & 0.804 \\
\hline Furniture layout & 1 & 5.6 & 39.1 & 47.7 & 6.6 & 3.53 & 0.744 \\
\hline Indoor plants, interior/exterior landscaping & 0 & 7.6 & 39.5 & 46.7 & 6.3 & 3.52 & 0.726 \\
\hline Presence of coordinated art objects & 1 & 11.5 & 42.1 & 41.4 & 3.9 & 3.36 & 0.775 \\
\hline
\end{tabular}

Notes:

*1: Least important; 2: Unimportant; 3: Neither important nor unimportant; 4: Important; 5: Very important.

${ }^{\dagger}$ Defined as the absence of unpleasant smell.

${ }^{\ddagger}$ Overall lighting: artificial and natural lighting combined. 
Table 4: Rotated component matrix of questionnaire items.

\begin{tabular}{llll}
\hline Item & $\begin{array}{l}\text { Component } \\
\text { Spatial }\end{array}$ & Environmental & Maintenance \\
\hline Indoor plants, interior/exterior landscaping & 0.729 & - & - \\
Furniture layout & 0.715 & - & - \\
Exterior view from the space & 0.713 & - & - \\
Presence of coordinated art objects & 0.699 & - & - \\
Pleasant color scheme & 0.699 & - & - \\
Architectural design of the space & 0.658 & - & - \\
Location and orientation of the space & 0.647 & - & - \\
Adequate illumination & - & 0.753 & - \\
Availability of daylight & - & 0.737 & - \\
Thermal comfort & - & 0.726 & - \\
Noise level & - & 0.694 & - \\
Air quality and freshness & - & 0.682 & 0.408 \\
Provision for hand hygiene & - & - & 0.746 \\
Proximity to wards & - & - & 0.643 \\
Cleanliness and ease of maintenance & - & 0.449 & 0.522 \\
Spaciousness of working areas & 0.475 & - & 0.487 \\
Percentage of explained variance (58.4) & 40.83 & 11.12 & 6.4 \\
Cronbach's $\alpha$ coefficient (0.901) & 0.863 & 0.852 & 0.736 \\
\hline
\end{tabular}


Table 5: Non-parametric test result.

\begin{tabular}{|c|c|c|c|c|c|}
\hline \multirow[t]{2}{*}{ Factor and questionnaire item } & \multicolumn{5}{|l|}{$p$-value } \\
\hline & Gender $^{\dagger}$ & $\mathrm{Age}^{\ddagger}$ & $\begin{array}{l}\text { Working } \\
\text { hours }^{\ddagger}\end{array}$ & $\begin{array}{l}\text { Length of } \\
\text { service }^{\ddagger}\end{array}$ & $\operatorname{Role}^{\dagger}$ \\
\hline \multicolumn{6}{|l|}{ Spatial } \\
\hline $\begin{array}{l}\text { Indoor plants, interior/exterior } \\
\text { landscaping }\end{array}$ & 0.529 & 0.258 & 0.297 & $0.047 *$ & 0.117 \\
\hline Furniture layout & 0.111 & 0.075 & 0.726 & $0.038^{*}$ & 0.207 \\
\hline Exterior view from the space & 0.904 & 0.355 & 0.471 & 0.115 & 0.358 \\
\hline Presence of coordinated art objects & 0.672 & 0.890 & 0.593 & 0.694 & 0.119 \\
\hline Pleasant color scheme & 0.222 & 0.060 & 0.118 & 0.642 & 0.241 \\
\hline Architectural design of the space & 0.684 & $0.047^{*}$ & 0.835 & 0.064 & 0.159 \\
\hline Location and orientation of the space & 0.251 & $0.028^{*}$ & 0.079 & 0.052 & 0.326 \\
\hline \multicolumn{6}{|l|}{ Environmental } \\
\hline Adequate illumination & 0.979 & 0.123 & $0.020 *$ & 0.332 & 0.986 \\
\hline Availability of daylight & 0.839 & 0.116 & $0.033^{*}$ & 0.619 & 0.62 \\
\hline Thermal comfort & 0.141 & 0.334 & $0.027 *$ & 0.991 & 0.428 \\
\hline Noise level & $0.037 *$ & $0.047 *$ & 0.326 & 0.494 & 0.980 \\
\hline Air quality and freshness & $0.038^{*}$ & 0.623 & 0.089 & 0.688 & 0.900 \\
\hline \multicolumn{6}{|l|}{ Maintenance } \\
\hline Provision for hand hygiene & $0.036^{*}$ & 0.868 & 0.259 & 0.155 & 0.875 \\
\hline Proximity to wards & 0.130 & 0.346 & $0.025^{*}$ & $0.001 *$ & 0.151 \\
\hline Cleanliness and ease of maintenance & $0.030 *$ & 0.833 & 0.087 & 0.062 & 0.656 \\
\hline Spaciousness & 0.987 & $0.005^{*}$ & $0.028^{*}$ & 0.367 & 0.885 \\
\hline
\end{tabular}

Notes:

${ }^{\dagger}$ Mann-Whitney U -test.

${ }^{\ddagger}$ Kruskal-Wallis test.

${ }^{*} \mathrm{p}<0.05$. 
